\title{
More Dominant in their Inactivity: Consumer Response and the Adoption of Digital TV in Australia
}

\author{
Niranjala D. Weerakkody \\ Deakin University, Geelong VIC, Australia
}

\author{
ninaw@deakin.edu.au
}

\begin{abstract}
After much hesitation, discussion, and power brokering, Australia adopted digital TV for its Free-to air broadcasting on January 1, 2001. However, by December 2002, only a few tho usand homes had adopted the technology. This paper examines the implementation and regulation of digital TV in Australia from the point of view of the 'established base' the new technology will replace, theories on diffusion and innovation of new technologies, and the Justification Model, which sees technology choice as social ga mbling. It then evaluates the various protectionist regulations and limitations imposed on the technology to safeguard the various stakeholders, the implementation strategies used, lack of digital content, marketing efforts, negative media coverage, and the economic realities of the technology, and argues that if consumers reject the technology altogether, it would lead to Australia missing the future applications of digital technology and the opportunity to address the issue of the 'digital divide' in the $21^{\text {st }}$ century.
\end{abstract}

Keywords: Digital TV, Australian broadcasting, Adoption and diffusion of digital TV, Broadcasting policy and regulation, Diffusion of innovations, Digital broadcasting in Australia, Broadcast spectrum allocation, Protectionism in broadcasting policy, Australian broadcasting policy, consumer response to new technology

\section{Introduction}

In what was termed a 'ground-breaking reform,' Australia adopted Digital Television (DTV) on January 1, 2001. In a media release, the Minister for Communications, the Information Economy and the Arts in Australia (DoCITA)- Senator Richard Alston announced that, "with digital television heralding an exciting new era in communication, these reforms will ensure that Australia is at the forefront of global developments...(and that).... Australians will experience in their lounge rooms the cinema picture quality and surround sound of High Definition Television" (www.dca.gov.au). However, according to some analysts, DTV in Australia "began with a whimper rather than a bang" (www.assg.org.au) and consumer interest in the new technology so far has been 'sluggish' (Hawthorne, 2002).

\section{What is Digital Media?}

Digital media refers to 'forms of media content that combine and integrate data, text, sound and images of all kinds, are stored in digital formats, and are increasingly distributed through networks such as those

Material published as part of these proceedings, either on-line or in print, is copyrighted by Informing Science. Permission to make digital or paper copy of part or all of these works for personal or classroom use is granted without fee provided that the copies are not made or distributed for profit or commercial advantage AND that copies 1) bear this notice in full and 2) give the full citation on the first page. It is permissible to abstract these works so long as credit is given. To copy in all other cases or to republish or to post on a server or to redistribute to lists requires specific permission from the publisher at Publisher@InformingScience.org based upon broadband fibre optic cables, satellites, and microwave transmission systems' (Flew, 2002; p. 11). Digital media content can be 'manipulated, networked, is dense, compressible, indifferent to the forms represented, its owne rship or creation, and its final uses because it simply sees content as a sequence of numerical zeroes and ones' (Flew, 2002, p. 11). 


\section{What is Digital TV?}

DTV, seen as the next evolution of television is compared to the change brought to vinyl records by compact discs. Instead of the waveforms used in analogue TV signals, DTV uses a digital sequence of zeros and ones. DTV is considered superior in engineering terms as it can overcome problems in overthe- air broadcasting caused by reflections from and obstructions by buildings and terrain features, interferences of electrical noise (eg. Motor vehicle ignition, overhead power lines, digital mobile phones and other transmissions), and fluctuations in signal strength as they pass through the atmosphere (www.digitaltv.com.au).

DTV can also deliver stunning pictures, surround sound and closed captioning as well as extras such as different camera angles, multi-channelling, delivering data such as the Internet, and provide interactivity to the viewers who can choose what to watch and when to watch it (www.abc.net.au). It can also provide access to websites, text-based information and back -channel links to the broadcasting service providers as well as develop new services that take advantage of the economies of digital spectrum use and enhance TV as a medium with the development of Internet-like capabilities (Flew, 2002; p. 111).

The two types of Digital TV used in Australia are Standard Definition TV (SDTV) and High Definition TV (HDTV). SDTV provides a similar picture to the existing analog service, but has the wide screen format, and may offer improved reception for many viewers along with all the benefits of DTV as they become available. In contrast, HDTV has outstanding image resolution, which is higher than of SDTV and the existing analog picture. HDTV also provides cinema quality viewing with the wide screen format and CD quality sound (www.abc.net.au).

\section{Theoretical Framework}

The Justification Model (Hemelink, 1988) sees decision- making about technology as a form of social gambling. This is due to our having only partial knowledge about a technology, its capabilities, potential applications, and effects. We also do not know what a technology will actually be used for once implemented or if it will be widely adopted or even adopted at all. When making policy about a new technology such as Digital TV, issues related to the 'established base'- the existing technology and infrastructure that the new technology will replace (Green, 2001) also need to be considered.

\section{Diffusion of Innovations}

Rogers (1995) and Manross and Rice (1986) have shown that adoption of a new technology into a given social structure involves an individual level decision-making, where it needs to be accepted by the ultimate user. The factors that affect adoption at the individual level are its: 1) perceived relative advantage, 2) compatibility, 3) complexity, 4) trialability, and 5) observability.

The relative advantage is the degree to which a new technology is perceived by the user as being superior to the one it replaces (the established base); compatibility is the degree to which a new technology is consistent with the adopter's prior experience, values and beliefs; complexity is the degree to which an innovation is perceived by the user as being difficult to understand; trialablity or divisibility is the degree to which an innovation can be given a small scale trial by a potential adopter or the extent to which parts of the innovation can be tried; and observability or communicability refers to the degree to which a new technology is visible to potential adopters. Innovations that are perceived by prospective users as high in relative advantage, low in complexity, high in compatibility, communicability and divisibility result in a more rapid rate of adoption. During the initial stages of adoption of a new technology, it is generally expensive and therefore affordable and attractive mainly to the groups called 'innovators'( $2.5 \%$ of the population), and the 'early adopters' - (13.5\% of the population), who are made up of younger, higher educated risk takers and those with high levels of disposable incomes (Rogers, 1995; 
Green, 2001). The rest will take a wait-and-see attitude for the price of the technology to drop due to economies of scale as the technology gets more widely adopted.

\section{New Technology-Same Old Functions}

Stephens (1998) shows how every time a new technology is adopted by society, it is initially used to carry out the same functions of the old technology or the established base. So when digital TV programming carries the same content as the analog signals (with only a better quality sound and picture), there is little incentive for viewers to invest large sums of money to buy DTV equipment.

\section{Method}

Using library research (Berger, 1998), the author examined the latest research, policies and existing literature on the subject of DTV via scholarly sources. The research also included the websites of all broadcast organizations adopting the technology and those of policy making bodies such as the DoCITA and the Australian Broadcasting Authority (ABA) and trade organizations related to DTV. In addition, a search of the Nexis.com (University Research Tool) database was carried out to identify articles published on DTV in the major international, national and regional newspapers for the last five years, to obtain an in depth understanding of the implementation of DTV in Australia.

\section{Issues Related to the Low Penetration of Digital TV}

According to existing literature and research, broader technical, political, and economic factors appear to be responsible for the consumer apathy towards DTV in Australia. These factors are: 1) constraints imposed by legislation on those granted the licences to broadcast on DTV, 2) protectionist policies introduced in a bid to safeguard the license holders from competitors, 3) implementation strategies, 4) consumer expectations and disincentives to adopt the technology and 5) Inadequate marketing strategies. Therefore, an examination of the history of DTV regulation, economic realities of the new technology, and the digital content so far available to consumers, would shed more light on the issue of low penetration of DTV in Australia.

\section{The history of digital TV regulation in Australia}

Governments are motivated to move from analog TV to DTV as the latter allows more efficient use of the broadcast spectrum and as a result, provides a source of revenue from the sale of spectrum access to other industries such as telecommunications. At the same time, however, they have to consider the interests of all stakeholders- especially consumers with low income who should not be burdened with a requirement to purchase any expensive new equipment and those in rural and remote areas who may be excluded from receiving its transmissions (Flew, 2002).

The adoption of digital TV was long under discussion, and faced much hesitation and power brokering. Officially, the process dates back to the first meeting of the Australian Broadcasting Authority Digital Terrestrial Television Specialist Group on the 26th of May 1993. The group presented its first report in 1995 and the final report on 30th January 1997, titled "Digital Terrestrial Television Broadcasting in Australia." In July 1997, The Australian Broadcasting Authority (ABA) released its response to the Specialist Group Report. In late 1997, the Department of Communication and the Arts and the Federation of Australian Commercial Television Stations in conjunction with the Australian Broadcasting Authority (ABA) and the Australian Broadcasting Corporation (ABC) conducted tests for the potential DTV technology for use in Australia. On 24 March 1998, the government of John Howard announced its DTV policy and between April 1998 and 15 July 1998, the necessary legislation was passed though Australian parliament and the Senate (www.digitaltv.com.au). The reforms of 1998 that led to the adoption of digital TV on January 1, 2001 meant that commercial and national free-to-air broadcasters (FTAs) were required to commence digital terrestrial broadcasting (DTTB) in the metropolitan areas by January 1, 2001 
and in regional areas from that day onwards so that all areas will have DTTB by January 1, 2004 (www.digitaltv.com.au/timelines.html). No new broadcasting licenses are to be issued at least till 2007 as a means of protecting the $\mathrm{A} \$ 1$ billion investment made by FTAs in converting to DTV as Australia is a comparatively small market of a population around 20 million (www.abs.gov.au).

These rules were seen as a victory for Kerrie Packer (the richest man and a major media owner in Australia, who owns Publishing and Broadcasting Limited or PBL) and his Channel 9 free-to -air TV station, and the channel 10 TV network owned by Conwest (of Canada). However, they are seen as disappointing to the datacasting aspirations of News Corporation (one of the three major media conglomerates in the world and owned by Australian-born Rubert Murdoch who is also a major owner of Australian media) and others such as John Fairfax and O\#mail, as they cannot air anything that looks like a $\mathrm{TV}$ program on the datacasting spectrum allocated for its functions. However, the free-to-air stations are also bound by restrictions, as they are required to transmit DTV at a lower standard than expected (Shanahan, 1999).

DTV was heavily regulated by Prime Minister John Howard's Government in an attempt to please most of the stakeholders concerned - viz. the existing FTAs who were considered the only group that has the market penetration necessary to make it financially viable, the public, and other interests. But no real incentives have been provided for the incumbent players (the FTAs), to encourage DTV adoption by consumers (News Limited, 2000).

\section{Prescriptive and protectionist policies}

New datacasting license holders on DTV are restricted on the video content they can carry which means they cannot broadcast news, current affairs, or sports programming and are limited to entertainment programming only up to 10 minutes in duration. Any news bulletins can only be up-dated every 30 minutes. These rules will allow viewers to access the Internet (but not Internet TV broadcasts) via DTV, e-mail, home banking and shopping services, education and interactive games. Prospective data casters argued that these restrictions destroy the main attraction of DTV (Shanahan, 1999) as datacasting is intended to cater to niche markets, the licenses will be of limited utility with limits on the entertainment content that can be provided (Rennie, 2001). This argument was proven in May 2001, when the Australian government had to call off the datacasting licensing auction due to lack of market interest, as the prescriptive rules imposed on the technology had inhibited market interest and scared off the News Corporation, Fairfax, and Telstra, which were the potential major bidders (Datacasting in disarray, 2001, May 10). However, the FTAs are also bound by restrictions, as they must transmit three types of signals - the existing analog, SDTV and HDTV. The analog signal is to continue for at least until 2008, so that audiences are not compelled to purchase -either set-top boxes that convert the analog signal to digital or the expensive SDTV and HDTV receivers immediately (www.dba.org.au).

\section{Customer response}

By the 20th of April 2001, only 3000 set top boxes have been sold (Only 3000 cough up for digital TV, 2001, April 30) and by 1 st of January 2002 or one year after its adoption, only a few thousand households had acquired the technology needed to receive digital TV signals in the form of set top boxes for the existing analog TV sets or new digital wide screen sets (Gilchrist, 2002; Hawthorne, 2002). By the end of January 2003 (or two years since implementation), only about 20,000 set top boxes have been sold (Familari, 2003; http://news.ninemsn.com.au ) in a nation with 10m TV households. In contrast, a comparable technology change viz. black and white to colour TV on March 1, 1976, saw 4\% of Sydney and 3\% of Melbourne homes adopting the technology by the end of that year and 54\% of Sydney and $48 \%$ of Melbourne homes adopting it by the end of 1977 or two years after implementation (ACNielsen, 1999). This was when a colour TV set cost A $\$ 2000$ in 1998 terms (Given, 1998). However, one should also consider that the change in the viewing experience for consumers moving from black and white to 
colour TV in 1976 far exceeds the change from today's colour TV to digital TV and therefore the conversion be less of a priority for consumers today.

\section{Cost of the new technology}

Today, a set top box that receives SDTV signals are priced between A \$300 and \$699 and a HDTV set top which can also receive SDTV ranges from A \$799-1079. Australian consumers purchase 1M new sets a year within the price range A $\$ 300-\$ 700$ (Familari, 2003). Research predicts that 46\% homes would adopt digital TV by 2008 , when the analog to digital conversion is expected to be complete (Rumble, Hoare, \& Schulze, 2002).

A recent proposal by the Department of Communication, Information Technology and the Arts (DoCITA) is to legislate mandatory built-in tuners for all new TV sets sold as a means of encouraging digital TV adoption. However it faces opposition from importers and retailers who fear limits to the variety of models available to the Australian market and retailers fear it would increase the price of a set by about A \$200 affecting their sales. However, this proposal was later modified to include only the more expensive sets (Day, 2002). The traders propose a combination of more channels, improved content and a clear policy on DTV as better incentives for the industry and consumers (Familari, 2003). It is worth noting that a similar scenario occurred in the USA, when the FCC (Federal Communications Commission) regulated built-in tuners for new analog TV sets (Moore, 2002).

\section{Digital content}

The lack of programming produced in digital is considered one of the factors responsible for the low DTV penetration in Australia so far because consumers watch TV for the content, not the technology (Clifford, 1992). He points out that the Cable News Network (CNN) did not gain high ratings or prestige until its live coverage of the 1991 Gulf War and that 'the ratings of TV stations had remained the same after the introduction of colour TV (from black and white TV) and improved only after program content improved' (Clifford, 1992, p. 67). Therefore, from the consumers' point of view, what is on DTV is more important than the quality of the picture and sound it provides.

Australian FTA television consists of the three commercial channels 7, 9, 10 and the two public broadcasters- the ABC (Australian Broadcasting Corporation) and SBS (The Special Broadcasting Service intended for multicultural programming). The Australian government has imposed quota requirements for HDTV at 20 hours per week on the FTAs who are granted the right to adopt DTV. These obligations will commence on 1st July 2003 for mainland (except Tasmania) capital cities and effectively not before 2005 in other areas. Any program transmitted in HDTV will be simultaneously broadcast on SDTV (www.dba.org.au).

Digital Broadcasting Australia (DBA) estimates that wide screen programming comprises $60 \%$ of current primetime viewing, with the Seven, Nine and Ten networks providing all their new drama, lifestyle, game show and sports programming in 16: 9 wide screen format. The Nine and Ten networks also provide all their news and current affairs programming on wide screen. The SBS and ABC also provide wide screen on selected programs, including Australian drama and various overseas drama and documentaries (www.dba.org.au). However, some of these HDTV programs will be initially 'up-converted' from existing analog programs, so the difference in quality may not be significant (www.abc.net.au). The highest programming content in the digital format is provided by the $\mathrm{ABC}$ which is a public broadcaster with 'ABC Kids' showing mostly reruns of popular kids' programs and 'ABC Fly' with its music, dance and discussion programming aimed at 15-25 year olds (Gilchrist, 2002). However, ABC like any public broadcaster worldwide has a lower viewer base than the commercial networks. Therefore the viewers who may be motivated to purchase the digital technology and thereby add to the number of households adopting it would be smaller in number, especially when its digital TV programming fare is catering to the under 25 demographic with little or no purcha sing power for the necessary equipment. 
More Dominant in their Inactivity

The ABC's digital content is expected to drive the growth of DTV but the genre restrictions it is faced with for multi-channelling may have to be lifted if its programming is broaden its appeal to consumers (Lawson, 2002). However, ABC- unlike other FTA channels, has universal reach especially in regional and rural Australia and is perceived by the community as providing a valuable service. It has also increased its ratings by $5 \%$ according to the last survey of 1999 (Ede, 2002).

The ABC spends about A\$7 M a year on its two digital channels and is sometimes asked the question if it could be better spent on mainstream programming (Simper, 2003a). Since 1996, the ABC has been faced with funding cuts from the Howard government and the $\mathrm{ABC}$ has threatened to 'dump the digital channels' and other recent analog programming initiatives if a 7\% increase in its funding for 2003-4 is not met. About $\mathrm{A} \$ 17 \mathrm{M}$ of this funding increase is earmarked for developing and expanding its digital network. The ABC argues that such funding for digital content has the potential to stimulate consumers to take up DTV (MacKenzie (2003). If these digital services, which are the only digital channels on air, are discontinued due to budgetary constraints, it may lead to an embarrassment for the government, which introduced DTV to Australia (Simper, 2003b). However, the Australian government cannot also be expected to foot the bill of the ABC digital channel and the public broadcaster, which has low ratings. Providing incentives for commercial broadcasters to produce digital content would be an alternative, but the free allocation of the broadcast spectrum already provided to them-(while the mobile phone spectrum was auctioned off at high prices) (Gilchrist, 2000), may be considered incentive enough by many.

\section{Discussion}

The library research indicated that the main problem faced by DTV in its early stages of adoption in Australia was the non-availability of equipment for purchase such as set top boxes for existing analog TV sets. This situation was attributed to the changes made to specifications that delayed the set boxes' arrival in the stores in Australia until mid- 2001. The high cost of wide screen digital TV sets, the continuation of the analog TV signals (the established base) until 2008, and the non-availability of sufficient new programming in the digital format, and restrictions on datacasters that can limit what digital TV can provide to Australian viewers, are factors that negatively affect the incentives for viewers to adopt digital TV. In other words, the low relative advantage (Rogers, 1995; Manross \& Rice, 1986) of the digital TV with reference to cost, programming and service choice, in comparison to the established base (Green, 2001) of analog TV for consumers, are the main factors that have so far limited the adoption of digital TV in Australia.

\section{Building Alliances}

When faced with arguments that an estimated five million British viewers watch Sky News on digital TV and that even Britain's failed digital network Independent TV (ITV) digital had 1.26 million subscribers when it folded in April 2001, Richard Alston explained that Sky, Britain's largest subscription television service was switching to digital, while in Australia, only FTA terrestrial services were required to make the change. "There is nothing stopping satellite providers in Australia from digitising, or Cable providers (called Pay TV) from doing so, but they haven't done it, although they may well do it as part of the FoxtelOptus deal (recently made for Pay TV)"... The debates in Australia has only been about a very narrow portion, which is free to-air terrestrial.... and that is not what is occurring (in Britain) at all" (http://news.ninemsn.com.au; Nine signs off on Foxtel deal, 2002 Decembe 28). Foxtel the current leader in Pay TV in Australia is part-owned by both Rupert Murdoch's News Limited and Kerrie Packer's Publishing and Broadcasting Limited (PBL) media conglomerates. Kerrie Packer also has a minority share in Optus Vision (a Pay TV service) (www.mitchells.com.au). Therefore, such an alliance for pooling resources could help improve audience take up of DTV.

Cable or Pay TV services were adopted in Australia in mid-1995 and have been slowly but steadily increasing their subscriber base (Kitney, 2002). So as Minister Richard Alston argues, digitising Pay TV 
signals could make adopting digital TV more attractive to subscribers who are also viewers of the FTA services. As Pay TV is subscribed to by households with higher disposable incomes, they may well be the ones who can also afford to purchase the set top boxes or wide screen TV sets required for receiving DTV signals. However, this digitalisation won't be attractive to Pay TV services, unless the investment can be justified with a large enough subscriber base.

The Minister also thinks that Australia should follow the US in using initiatives to encourage take up of digital TV by viewers with the requirement of mandatory digital tuners to be embedded in all new TV sets sold (Hawthorne, 2002). "The free-to-air networks say that there should be a common set top box mandated with a dual tuner to accommodate either satellite and cable or satellite and terrestrial or cable and terrestrial. ......We (Australians) are looking at that..... I think it has a number of complications. There are some things you can do to stimulate it (the adoption of digital TV), but at the end of the day it's going to be a matter of how the consumers respond and all we can do is facilitate the framework" (http://news.ninemsn.com.au).

\section{Patterns of Adoption}

The early stage of adoption of a new technology that Australia is going through with DTV can be seen as that belonging to the early adoption stage where only $2.5 \%$ of the population of 'innovators' will adopt it and fits with the "S" curve for the rate of adoption of a new technology (Rogers, 1995; Green, 2001). As the current cost of DTV is high, at this stage, it will only appeal to those who can afford it or are adventurous, in keeping with that group's characteristics. The slow rate of adoption therefore should not be labelled 'a failure' or 'bad policy making,' as the scenario so far appears to fit with the existing theories (Rogers, 1995; Green, 2001). This outcome also agrees with Hemelink's (1988) theory of policy making with reference to any new technology as being 'a gamble' under the Justification Model.

\section{Cost of the Technology}

Making the technology (eg. the set top box) affordable to a wider consumer base and providing more programming content produced in digital format - especially with sports and drama programming, which benefit the most from the wide screen format, will be one way to increase the rate of adoption. This should provide the digital signal more attractive to viewers while the established base (Green, 2001) of the analog signal is still available.

\section{Digitising pay (Cable) TV}

In the United Kingdom (UK), once the News Corporation-owned BSkyB satellite service provided the set top boxes free to its Pay TV subscribers, the take up of digitalized Pay TV is reported to have drastically increased and the service is held up as an example for Australia to follow (Day \& Bryden-Brown, 2001). However, the larger population and the small geographic size of the UK in comparison to Australia raise the question whether following the UK example is suitable for Australia. The recent failure of ITV- the other smaller DTV service in the UK sends warning signals that the success of digitalised Pay TV is not a given (Kitney, 2002). In Australia, for such a service to succeed, anti-siphoning regulation on popular sporting events (which specifies that they should not be exclusive to Pay TV) may have to be removed to make Pay TV attractive to subscribers. However, Pay TV that was introduced in mid-1995 in Australia only had about 800,000 subscribers at the end of 2002 (Turner, 2002). The main reason for the low take up of Cable is the cost of installation and monthly subscription, which again would raise the question as to its suitability as an alternative to increase DTV adoption.

\section{A common set-top box}

Another strategy worth considering is the Channel 10 Network's proposed common digital set top box or 'dual tuner' for both FTA and Pay TV, which the ABC has supported and would reduce hardware 
costs to consumers (Lawson, 2002). A common set top box for FTA digital TV and Pay TV (Lawson, 2002) as well as Sony Play Station 2 (expected to introduce a digital tuner and Internet browser to their games consoles soon) (Turner, 2002) could be a possibility with an alliance between many players, even though it will then raise issues of the convergence of media technologies, industries, and functions resulting in limited diversity and monopolies (McChesney, 1998).

The more sophisticated digital set top boxes can be used for collecting ratings data for audience measurements via its 'back channel' function (Garland, 2002), which is a more reliable method than the current use of ratings panels (Thomas, 2002), provided the DTV penetration is high enough. As the Australian ratings organization OzTAM is owned by the three FTA broadcast networks, they along with Pay TV could be encouraged to invest in a plan to increase TV set top box or DTV adoption. Pay TV can use the same boxes for their billing functions. Such an alliance may also be able to either provide set top boxes free or at a subsidized rate to consumers. In the US, industry competitors- either voluntarily or at the behest of the government, formed alliances and pooled resources to develop suitable technical systems for their digital broadcast systems (FCC, 1996; Warley, 2002). However, Australia with no such precedents of alliance-formation may find the possibility of one now a challenge more than ever as shown by the reluctance of Foxtel partners for the dual tuner had indicated, where partners of Foxtel PBL, News Corporation and Telstra (telecommunications), could not agree on a dual tuner for both FTA and Pay TV as Telstra wanted to protect its cable system as exclusive (Kitney, 2002).

\section{Built-in tuners}

However, the built in digital tuners- only for the larger screen sizes initially) could be a better alternative than a dual or multiple tuner, as a non- mandated requirement. Most of the people who buy the $1 \mathrm{M}$ new TVs in Australia each year may be willing as well as able to afford the additional \$200 dollars towards DTV instead of having to spend thousands for DTV. A considerable demand for such sets would drive the price of these sets down fast.

\section{Marketing}

DTV adoption is also claimed to be suffering from the lack of marketing efforts. Consumers appear to be confused about the technology, its capabilities and its complex implementation. Until recently, sales personnel of TV retailers were not adequately trained to handle inquiries of prospective buyers of DTV equipment in a meaningful manner. In November 2002, Digital Broadcasting Australia (DBA) released a DVD called "What is Digital TV?" for the information of sales staff and prospective buyers of DTV sets, which can be seen as a step in the right direction (Moullakis, 2002). According to Jock Given- a researcher into DTV, "Free-to-air broadcasters need to convince consumers with budgets that digital TV is a better option than a computer, an Internet connection or a DVD" (Mitchell, 2002, p. 30). The Internet currently providing $2 / 3$ of the functions of those promised by DTV also makes the new technology less revolutionary for consumers (Mathieson, 1998; Familari, 2003) and should be a factor to be considered for inclusion in any marketing efforts.

\section{Negative media coverage}

Negative press coverage about the 'failure' of DTV so far in Australia- mostly published in newspapers owned by Fairfax and News Corporation who lost out in the bid for DTV (Datacasting in disarray, May 10, 2001); Barry 2001; Day \& Bryden-Brown, 2001; Gilchrist 2000 \& 2002; Lucas, 2001; Only 3000 cough up for digital TV, 2001 April 30; Day, 2002; Melloy, 2002; Mitchell, 2002; Rumble, Hoare \& Schulze, 2002; Schulze, 2002)- some even before or soon after the implementation of DTV, discourage the average consumer from adopting the technology as they need to be convinced that the technology is here to stay. As it stands today, the strict regulatory restrictions and the lack of marketing efforts have 
led DTV in Australia to be 'just pretty pictures for those who can afford them' or a 'boutique market for the rich' (Mitchell 2002).

\section{Conclusion}

As TV is accessible to a larger proportion of Australian homes than the Internet and TV is accessible to those who are not computer literate, DTV will be important to Australian consumers in the long run. Failure of DTV would also mean that its future applications would be either delayed or lost Australia (Flew, 2002; Shafer, 1992) especially when nations such as the UK are already established at the cutting edge of DTV (Day \& Bryden-Brown, 2001).

Interactivity, which is available with DTV, is considered empowering to consumers. However, current analog TV viewing habits of the majority of consumers may not be compatible with interactivity (Rennie, 2001). The same can be said about accessing the Internet on DTV as current viewers are used to TV viewing as a leisurely and passive activity apart from using the remote control while sitting comfortably (Kubey \& Csikszentmihalyi, 1990), which may not be compatible with the active individual involvement required of consumers when accessing the Internet for non-broadcast content today. Ho wever, with the future generations of adults currently growing up on heavily using the Internet, this pattern might change or be different.

DTV that began its service with a zero base of receivers needs to offer 'added value' or benefits such as Interactive Virtual Reality (VR) and transactional services or perceivable or understandable benefits to consumers in order to succeed. But these services may take years of development and / or implementation (Papathnassopoulos, 1998). Without a large enough consumer base, these expensive alternatives will not be financially viable for broadcasters to provide. This leads to a 'catch-22' situation where consumers are inhibited from investing in the set- top boxes or new DTV receivers, as there isn't enough digital content or additional services to warrant the expense. Broadcasters on the other hand, are inhibited from providing costly new content and services unless the consumer base is large enough to warrant their costs and investment.

Unfortunately, reducing the attractiveness of the new medium due to restrictions imposed on it for safeguarding the various stakeholders and their interests, or the economic realities of providing 'added value' to the content, can destroy consumer interest and result in Australia losing an opportunity to bridge the 'digital divide' via access to the Internet with DTV by consumers not yet comfortable using the Internet via computers (Flew, 2002; p. 112). Even though the government may have endeavoured to protect the interests of consumers in their policy initiatives, so far, it has not been able to influence the desired consumer behaviour in the adoption and diffusion of DTV. Even though Australians in general are considered to have a penchant for new technology (Melloy, 2002), digital TV has so far failed to attract them in significant numbers. In other words, it has resulted in consumers becoming more active in their inactivity than active government policy or industry strategies. This situation agrees with Owen (1999), which argues that after implementation of a new technology, government policy may even be superfluous to adoption and consumer beha viour.

\section{References}

ACNielsen. (1999). Australian television: A ratings history 1956-1998. ACNielsen Australia.

Barry, Y. (2001, January 2). Silence deafening for digital TV. Herald Sun (Melbourne), p. 2.

Berger, A. A. (1998). Media research techniques (2 ${ }^{\text {nd }}$ ed.). Thousand Oaks, CA: Sage.

Brown, A. (2002). Media ownership in the digital age: An economic perspective. Media International Australia-Culture and Policy, No. 95, 49-61.

Clifford, J. (1992). HDTV from a business perspective. In L. CasaBianca (Ed.), The new TV: A comprehensive survey of High Definition television. (pp. 65-69). Newport, CT: Meckler. 


\section{More Dominant in their Inactivity}

Datacasting in disarray. (2001, May 10). Australian Financial Review, p. 1.

Day, M. (2002, May 1). TV bungling not a pretty picture. The Daily Telegraph, p. 24.

Day, M. \& Bryden-Brown, S.(2001, July 5). Digital dreaming: How the UK got interactive TV right and we didn't. The Australian, p. M1.

Ede, C. (2002, September 19). New ABC chief in plea for more cash. (Brisbane) Courier Mail, p. 7.

Familari, P. (2003, January 30). Importers fear jump in TV costs. Herald Sun, p. 14.

FCC (1996). Fourth report and order. Adopted December 24, 1996. Retrieved on January 15, 2003 from http://www.fcc.gov/Bureaus/Mass Media/orders/1996/fcc96493.txt

Flew, T. (2002). New media: An introduction. Melbourne: Oxford University Press.

Garland, (2002). The future of television audience measurement: Nielsen media research's view. Media International Australia-Culture and Policy, No. 105, 49-54.

Given, J. (1998). The death of broadcasting?: Media's digital future. Sydney: University of New South Wales Press.

Gilchrist, M. (2000, May 13-14). Political spectrum. The Weekend Australian, p. 29.

Gilchrist, M. (2002, January 5-6). Digital TV flops into few lounge rooms. The Weekend Australian, p. 9.

Green, L. (2001). Technoculture: From alphabet to cybersex. Sydney; Allen \& Unwin.

Hawthorne, M. (2002, October 2). Mandatory digital TV considered. The Australian - IT Section. (http://www.australianit.news.com.au/articles)

Hemelink, C. J. (1988). The technology gamble. Informatics and public policy: A study of technology choice. Norwood: Ablex.

Kitney, D. (2002, September 16). Multichannelling in competition is competitive: ACCC. Australian Financial Review, p. 14

Kubey, R. W. \& Csikszentmihalyi, M. (1990). Television and the quality of life: How viewing shapes everyday experience. Hillside, NJ: Lawrence Erlbaum Associates.

Lawson, A. (2002, September 19). ABC heavyweight steps into the Pay TV stoush. The Age (Melbourne), p. 2.

Lucas, S. (2001, January 3). Digital TV 'fiansco and flop'. The Canberra Times, p. A1.

McChesney, R. W. (1998). Media convergence and globalization. In D. K. Thussu (Ed.), Electronic empires: Global media and local resistance (pp. 27-46). London: Arnold.

Mackenzie, K. (2003, January 30). ABC plans content to drive digital TV. The Australian-NSW Country edition, p. B7.

Manross, G. G. \& Rice, R. E. (1986). Don't hang up: Orgnaizational diffusion of the intelligent telephone. Information and Management, 10, 161-175.

Mathieson, C. (1998, March 14). TV revolution puts viewers in box seat, The Weekend Australian, p. 8.

Melloy, N. (2002, January). What's on. Courier Mail (Brisbane), p. 2.

Mitchell, S. (2002, September 17). Digital TV: just slow off the mat or dead in the water? The Australian, p. 30.

Moore, S. (2002, August 24). FCC should leave digital television to a free market. Chicago Sun Times, p. 20.

Moullakis, J. (2002, November 8). Digital TV shake up. Australian Financial Review, p. 8.

News Limited (2001). A submission to the Senate Legislation Committee on Environment, Communication, Information Technology and the Arts Inquiry into the Broadcast Services Amendment (Digital TV and Datacasting) Bill 2000. Canberra, Australia: Senate Environment, Communication, Information Technology and Arts Committee.

Nine signs off on Foxtel transmission deal. (2002, December 28). (Brisbane) Courier Mail, p. 37.

Only 3000 cough up for digital TV. (2001, April 30). Sydney Morning Herald, p. 27.

Owen, B. (1999). The Internet challenge to television. Cambridge, MA: Harvard University Press.

Papathanassopoulos, S. (1998). The development of digital television in Europe. Media International Australia-Culture and Policy, No. 86, 77-86. 
Rennie, E. (2001). Community television and the transition to digital broadcasting. Australian Journal of Communication, 28(1), 57-68.

Rumble, C., Hoare, D., \& Schulze, J. (2002, April 29). Push grows for digital TV strategy review. The Australian, p. 30.

Rogers, E. M. (1995). Diffusion of innovations ( $4^{\text {th }}$ ed.). New York: Free Press.

Schulze, Jane (2002, February 7). Two-way TV: Will digital television turn you on? The Australian-Media Section, p. 2-3.

Shafer, R. J. (1992). NASA's advanced video systems program. In L. CasaBianca (Ed.). The new TV: A comprehensive survey of high definition television (pp. 129-134). Westport, CT: Meckler.

Shanahan, Dennis (1999, December 18-19). Digital TV rules limit outsiders. The Weekend Australian, p.1.

Simper, E. (2003a, January 18-19). ABC puts digital on the line. The Weekend Australian, p. 3.

Simper, E. (2003b January 18-19). Please sirs, can we have some more? The Weekend Australian, p. 25.

Stephens, M. (1998). "Which communications revolution is it anyway?" Journalism and Mass Communication Quarterly, 75 (Spring), 9-13.

Thomas, A. (2002). Afterword: Developments in new media audience research. Media International Australia-Culture and Policy, No. 105, 35-39.

Turner, A. (2002, August 6). Sony Plays up its role of saviour. The Age (Melbourne), p. 3.

Warley, S. (2002, December 16) Selling content, not technology: iBlast. TvSpy online. Retrieved December 17, 2002 at http://www.tvspy.com/nexttv/nextttvcolumn.cfm?t_nextttv_id=821\&page=1\&tcontent_cat_id=10 